\title{
PAUL WURTH COKE OVEN MACHINES TECHNOLOGY A PRACTICAL BRAZILIAN EXAMPLE*
}

\author{
Alessandro Molinari ${ }^{1}$ \\ Giovanni Siri \\ Helênio Resende Silva Junior ${ }^{3}$
}

\begin{abstract}
In recent times, coke oven machines are acquiring a more prominent role in the coke making process. Apart from the traditional handling of the coal and coke flow, nowadays these machines are also deeply involved in all environmental and process control aspects. Paul Wurth coke oven machines have been developed by Schalke to meet the most recent requirements in terms of emissions control, automation, instrumentation, operability and maintainability. In CSP, Ceará, the new coke making plant represents the status of the art of the technologies applied to the whole coking process; starting from the Coke Oven Batteries and the Gas Treatment Plant developed by Paul Wurth up to the Coke Machines supplied by Schalker Eisenhütte, whose technology is now part of Paul Wurth coke making products portfolio. Present paper describes the plant configuration focusing on Coke Oven Machines and the key factors which are guarantying the success of the project.
\end{abstract}

Keywords: Coke oven machines; Pusher; Transfer; Charging; Quenching; Loco. 


\section{PROJECT FEATURES}

CSP - Companhia Siderúrgica do Pecém is a Company formed by Brazilian Vale and South Koreans Dongkuk and Posco with the scope to develop steel industry and occupation in Ceará State, Brasil.

The construction of CSP Plant in Pecém started in 2012 and is presently proceeding to complete the 1st Integrated Steel Making Plant in Northeastern Brasil. The whole plant capacity will be in the first phase 3 million tons of steel slabs/year, the doubling of the capacity is foreseen for the second stage.

CSP batteries are the first ones based on tall oven technology $(7,6 \mathrm{~m})$ ever built in Brasil, thanks to the reduced number of pushing per day, they can guaranty the maximum performance in terms of environmental protection and long lasting operations.

\subsection{Plant Configuration}

CSP Coke Making Plant is mainly composed by following units:

- Two (2) Batteries 50 Ovens each - Jumbo Oven Type (COB)

- One (1) Coal Tower

- One (1) Wet Quenching Plant

- One (1) Coke Wharf

- One (1) Gas Treatment Plant (GTP) made in cooperation with DMT And by two sets of coke machines made of:

- Two (2) Pusher Machines

- Two (2) Coal Charging Cars

- Two (2) Coke Transfer Cars

- Two (2) Coke Quenching Locomotives

- Two (2) Coke Quenching Cars for wet quenching

- Four (4) Door Service Cars

- One (1) Coke Side Pushing Emissions Collecting System

One set will be in operation on the two batteries, the second one will act as stand-by. The design production capacity is the following:

- Raw Coke - 1,345,755 tpy

- Clean Coke Oven Gas - 87,500 Nm³/h

\subsection{Oven Main Dimensions (Hot)}

Length:

Height:

Oven length between door plugs

Oven length between buck-stays

Oven height to roof

Coal charging height

Width:

Oven width in average

Oven taper

Oven pitch (center to center)
$17,440 \mathrm{~mm}$

$18,310 \mathrm{~mm}$

$7,600 \mathrm{~mm}$

$7,175 \mathrm{~mm}$

$550 \mathrm{~mm}$

$50 \mathrm{~mm}$

$1,650 \mathrm{~mm}$

Here below the main cross section of the batteries is shown (Figure 1). 


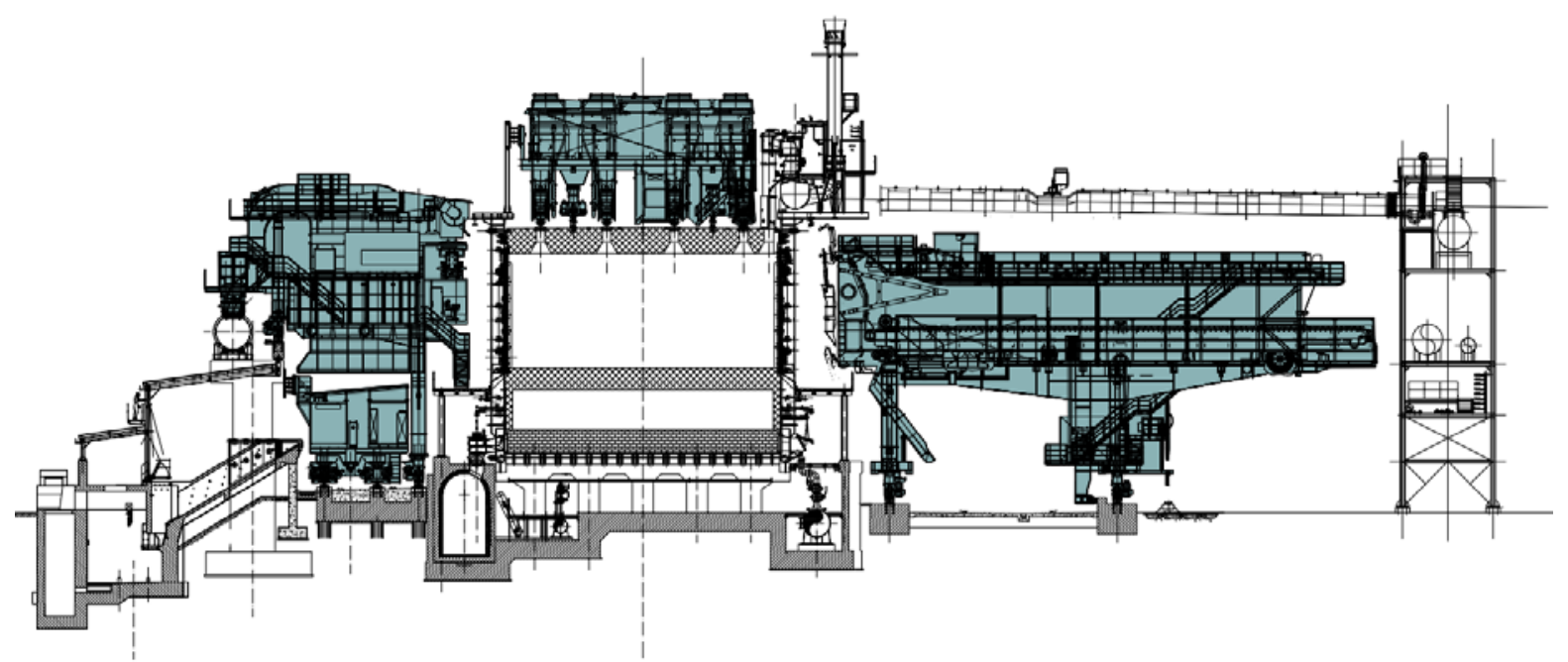

Figure 1. COB Cross Section

\subsection{Coke Oven Machines}

\subsubsection{General aspects}

The whole sets of machines are designed taking into maximum consideration pollution control regarding:

- Emission during charging

- Emission on top coke side door when opening the door

- Emission during coke pushing on coke side

- Emission at oven doors during coking period

They represents the highest level of the technology developed by Schalke during more than hundred years and recently applied in several Jumbo ovens worldwide.

\subsubsection{Coal charging cars}

For CSP plant two single spot coal charging cars have been supplied (figure 2); each one equipped with the most modern technologies regarding pollution control and safe and efficient operations.

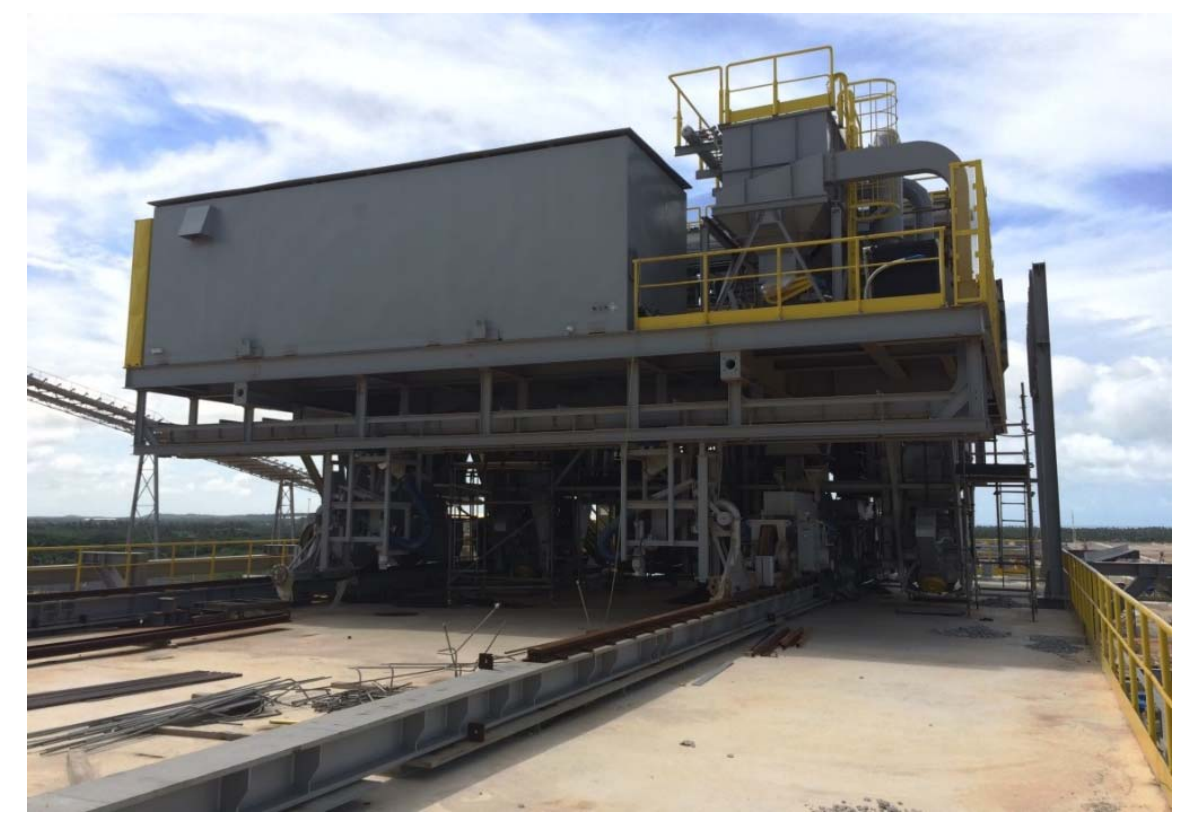

Figure 2. Charging Car 
- Rotary gates

- Sealed telescopes

- Lid lifters

- Auxiliary lid lifters at oven $\mathrm{N}+2$

- Lid luting system

- Oven top vacuum cleaner

\subsubsection{Travel drives}

The coal-charging car is furnished with 16 wheels. These 16 wheels are supported in 4 four-wheel bogies. Each four-wheel bogie consists of 2 two-wheel bogies. One wheel in each two-wheel bogies is driven.

The whole system is connected to the machine framework via a spring loaded suspension beam which has the aim to eliminate all the vibrations and reduce the loads to oven roof refractory.

In case of failure of one electrical motor, the machine is in any case able to operate at a reduced speed.

\subsubsection{Schalke controlled charging}

The SCHALKE controlled charging system was developed with the objective to reduce the emissions occurring during charging on batteries down to a level tolerated by law with a minimum of investment and operation cost.

In CSP the last development of this system has been applied in combination with the single oven pressure control system (SOPRECO $®$ ) installed by Paul Wurth on the two batteries.

The above arrangement represents the status of the art for Coal Charging for coke oven batteries. As a matter of facts it is able to guaranty the best performance and long lasting operation at design conditions.

The system is based on the following concepts:

- Optimal cleaning of charging frames

Frame cleaners guaranty that the contact surface with the telescope tip is always perfect cleaned, the scraping is performed via specially designed brushes actuated by a rotary drum.

- Perfect gastight charging system

The charging equipment creates a sealed connection between charging hole frame and telescope and has gastight seals at all telescope links and at the discharge gate as well as at the coal hopper filling opening. This charging equipment is gastight up to an overpressure of $20 \mathrm{~mm}$ water gauge.

The seal between charging hole frame and telescope and between bottom and top telescopes is created by using hydraulic cylinder to press the two metal parts against each other. The cylinder force is applied during the entire charging process. However, the sealing system will not conflict with the selfadjustment features of the telescope in case there is an offset between the 
centre of the charging hole lid and the centre of the telescope or a deviation in lid elevation.

The connection between the top telescope and the screw feeder outlet is created with the help of a well-protected compensator.

The discharge gate used in the gastight charging equipment is a Schalke development. It is integrated in the screw feeder outlet and prevents the coal from spilling onto the oven deck. During charging, it opens the screw feeder outlet completely. The gate is actuated from the outside of the screw feeder construction.

The seal with the coal hopper filling opening is created with the help of a coal plug, i.e. after charging, a certain amount of coal remains both in the screw feeder and in the hopper.

In the following (Figure 3) an overview of the system is shown.

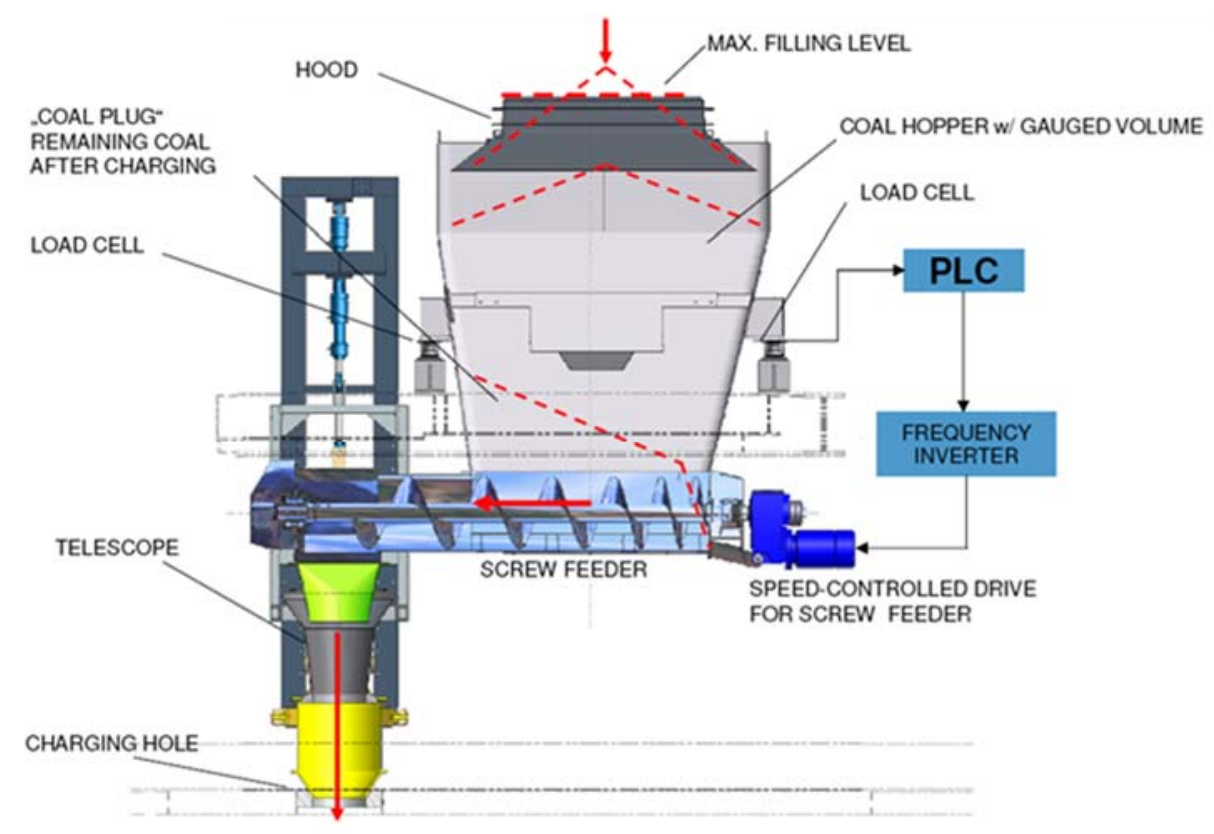

Figure 3. Charging System

- Continuously controlled coal charging

Levelling and charging at the same time creates a blockage of the gas passage, causing an overpressure at the telescope, on the one hand, and the built-up of peak amounts of charging gas which would have to be conveyed through the standpipe, on the other hand.

In order to overcome this bottleneck, a charging system which minimizes the number of levelling strokes has been introduced, as an optimum, the charging process should take place without levelling at the same time, i.e. only when charging has been finished, one levelling stroke is to be carried out.

The possibility to introduce the system "charging without levelling at the same time", of course, depends on the oven geometry.

It must be possible to build up the coal peaks inside the oven in such way that the volume of the coal piles an top of the levelling line balances the volume of the valleys below the levelling line. During the entire charging time, a free gas passage between coal pile and oven roof must be provided. The coal pile is normally built up inside the tapered charging hole without blocking the gas 
passage. Another pre-condition is that a free space between top of leveller bar and oven roof is provided during levelling.

Only a charging system with a high accuracy in building up the coal piles inside the oven can achieve such a constant free gas passage.

- Efficient levelling performed by Schalke Pusher Machine

The leveller bar installed in the Pusher Machine is designed work in perfect combination with the charging car, its shape guarantees a minimum bending during levelling and a good resistance to thermal stress.

\subsubsection{Lid lifters}

The rotary magnetic lid lifters guided by the centering pins installed on charging lids, can follow the eventual misalignment occurring to the lids themselves. They are equipped with detection devices capable to verify the presence and correct engagement of the lids. As all the other functional units of Schalke charging car, the whole hydraulic actuation is arranged above the top platform, in order to be completely protected from flames and heat.

\subsubsection{Auxiliary lid lifters at oven $\mathrm{N}+2$}

For CSP Project, a second row of lid lifters have been arranged in order to manipulate the lids opened for decarbonizing operations.

The special electro-magnets are arranged on a cardanically suspended cross beam. Due to the cardanic suspension, the lids are concentrically replaced even when they have not concentrically been lifted.

\subsubsection{Lid luting system}

The special designed horizontal tanks, have the scope to distribute the luting liquid along the four charging holes avoiding sticking problems.

The mixture is prepared by a stationary device installed on coal tower and loaded onto the machines on shift basis.

\subsubsection{Oven top vacuum cleaner}

OTVC installed on CSP charging car is a fully automatic device capable to operate at oven $\mathrm{N}-2$ (the oven charged by the machine during previous sequence).

This device is mainly formed by three components:

- Two shuttle suction tips moving along the oven roof

- The main duct

- One bag filter placed on the machine main platform

Thanks to Schalke design the movable shuttle is connected to the fixed part (bag filter) without a flexible hose. In this way the maximum reliability is assured.

\subsubsection{Coke pushing machines}

Two modern single spot pusher machines have be arranged at $\mathrm{COB}$ side with the purpose to push the ready coke and to perform the levelling operations in coordination with the charging cars. 


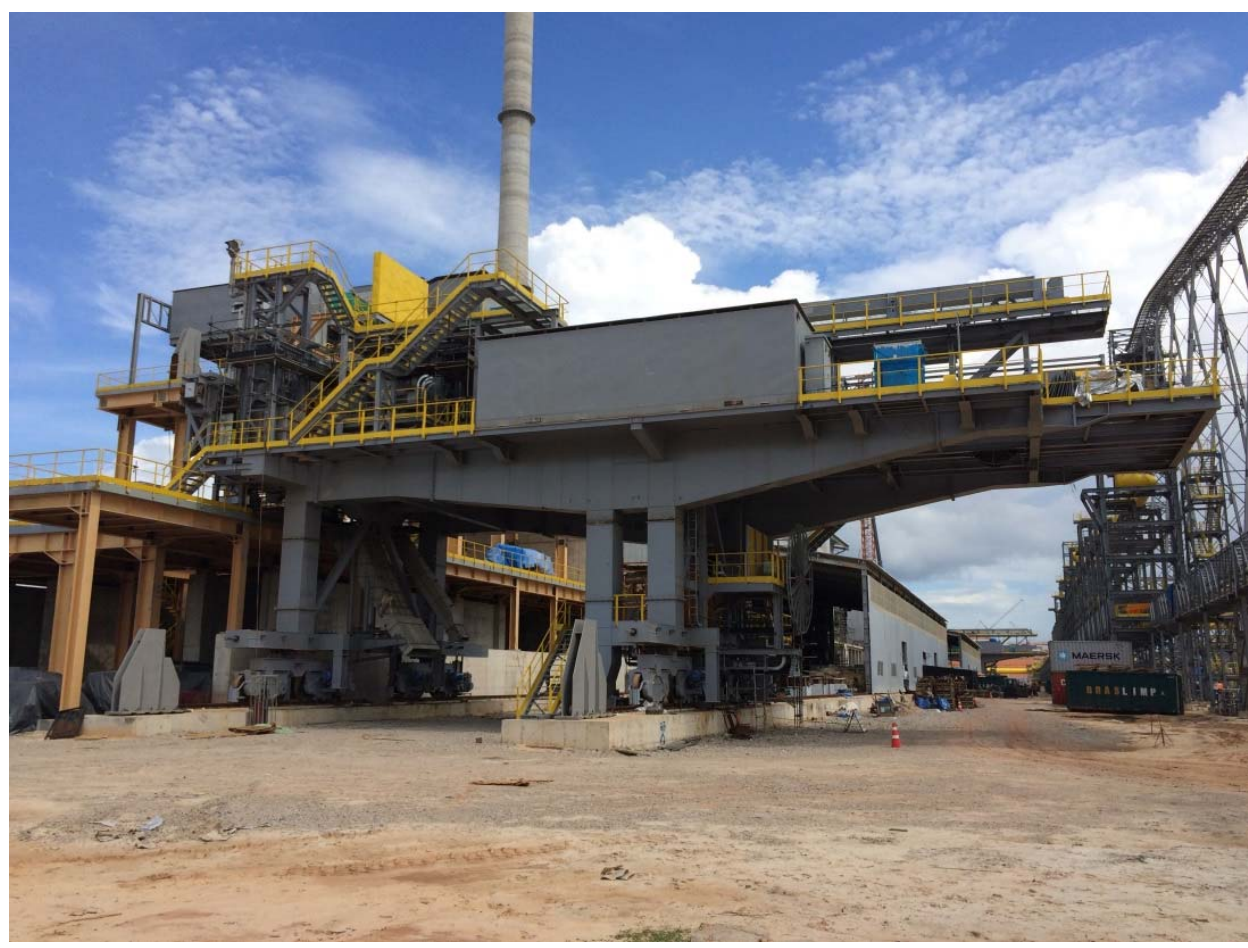

Figure 4. Pusher Machine

In addition to the above, the machines are equipped with the tools necessary to clean both the oven doors and frames.

The main functional units are listed below:

- Travel drives (boogies)

- Pushing device with decarbonizing system

- Leveling device with smoke sleeve and coal spillages collecting device

- Coke spillages collecting device with quenching system

- Door extractor (adaptive type)

- Door cleaner

- Frame cleaner

\subsubsection{Pusher device}

It is the task of the pushing equipment to push the ready carbonised coke out of the oven, through the coke guide into the quenching car.

The pusher device is situated on the lower machine platform and consists of

- the pusher bar drive,

- the pusher bar,

- the pusher bar head with the plough shoe and roof decarbonising system

Two fixedly installed pipes on each side of the pusher bar supply the de-graphitizing air to nozzles at the top of the pusher bar head with the functions of:

- oven top decarbonising

- stand pipe decarbonising

The height adjustable sliding shoe underneath the front part of the pusher ram is equipped with a changeable wearing plate. It supports the pusher bar inside the oven during pushing.

The pusher head is also equipped with a height adjustable mechanic carbon scraper. 
Schalke has always improved his pusher ram design, today the procedures applied for the fabrication of these component are the only one qualified for the application on tall ovens.

\subsubsection{Levelling device}

Levelling device has the scope to level the coal peaks inside the oven after charging to achieve an even top surface of the charged coal inside the oven.

The levelling device is situated on the upper machine platform, with its centreline two oven pitches away from the centreline of the pusher bar on the pusher bar right side when facing the oven and consists of:

- the leveller bar drive

- the leveller bar

- the leveller bar support roller

- the leveller door manipulator

- the smoke sleeve and the spillage coal collection system

- the movable platform in the smoke sleeve area

The leveller door manipulator is installed at the utmost front end of the leveller bar, facing the oven. It opens and closes as well as unlocks and locks the leveller door.

In order to avoid the escape of flames and smoke through the open leveller door, a smoke sleeve with an air curtain has been provided. Furthermore a spillage coal chute is situated in front of the smoke sleeve. This chute swings towards the oven door and collects as well as guide spillage coal from the leveller door opening to the leveller coalbunker.

The leveller bar support rollers are installed in several roller stands. The rollers itself are manually adjustable to compensate all deviation.

The ladder type leveller bar is of welded construction and furnished with a changeable front portion. The leveller bar design and the levelling procedure are chosen with respect to minimize the bars deflection.

\subsubsection{Spillage coke collection system}

The machine is equipped with a device which collects the spillage coke resulting from oven servicing. After the oven has been closed, the collected spillage coke is transferred via a chute into a storage bin at the machine.

The device is located underneath the pusher bar and consists out of a movable and tilt able spillage coke collection pan with integrated quenching system, a transfer chute and a spillage coke storage bin with discharge gate.

Whenever necessary, the storage bin can be emptied with the help of a hydraulic cylinder operated clamshell gate at the designated positions into a dedicated stationary box.

\subsubsection{Door extractor}

The adaptive door extractor is positioned in a steel structure beside the pusher bar and consists of:

- a robust travel beam with guide rollers, which is rested in a carriageway

- the swivel arm, which is attached via the upper and lower pivot bearings to the front portion of the travel beam

- the door extractor head, which is attached via a pivot bearing to the swivel arm

All travelling and lifting movements are effected by means of hydraulic cylinders. Turning the door in and out of oven axis is executed via a curved track. 
The door extractor is provided with a door position detection and memory system capable to memorize the height and inclination of each oven doors.

The inclination and height detection and memorizing system ensures the highest possible cleaning efficiency of the door cleaner, prevents damages to the doorsealing strip during door extraction and thanks to the capability to handle significantly inclined doors, grants the highest longevity of the whole construction.

\subsubsection{Door cleaner}

The door cleaner is installed in the steel structure on the side of the door extractor. After the door has been extracted and the door extractor has been returned to its home position, the door is pivoted by $90^{\circ}$ via curved track to be in line with the centre line of the door cleaner.

Furthermore, the door extractor will move the door in height and inclination into the cleaning position to achieve highest cleaning efficiency.

Door cleaning takes place while the coke is being pushed and the frame is being cleaned.

The door-cleaning device consists of a cleaning head and a long travel jib with steel structure. The cleaner head "system SCHALKE" made of a robust hollow profile design is attached to the moving device by stable guide frame. The guide frame also accommodates the hydraulic cleaning cylinder as well as the spring-suspended guide rollers of the tool holder and the top and bottom horizontal cleaners. The vertical cleaning cylinder is adjustable and is mounted on shock absorbing elements.

All scrapers are arranged on spring loaded adjustable devices in order to allow a smooth and safe cleaning action.

\subsubsection{Frame cleaner}

The frame cleaner is positioned in a steel structure beside the pusher bar, but on the other site as the door extractor and consists of:

- a robust travel beam with guide rollers, which is rested in a carriageway,

- the swivel arm, which is attached via the upper and lower pivot bearings to

- the front portion of the travel beam, and the frame cleaner head, which is attached via a pivot bearing to the swivel arm.

The cleaner head, "system SCHALKE", supported by a hollow profile structure is hinged at the pivoting part by means of a stable guiding frame.

\subsubsection{Coke transfer cars}

The main features of the new machines are, as described below, considering the state of the Art technology in the fields of emission control, operation reliability and low maintenance:

- Installation of a pushing emission control system with land based filter plant connected to the machine's hood system

- Installation of a door emission collection system. This system collects the emission escaping from the open oven chamber and from the door in cleaning position and conveyed by thermal effect to the top of the machine

- Installation of a spillage coke collection device.

- Installation of door cleaner

- Installation of frame cleaner 


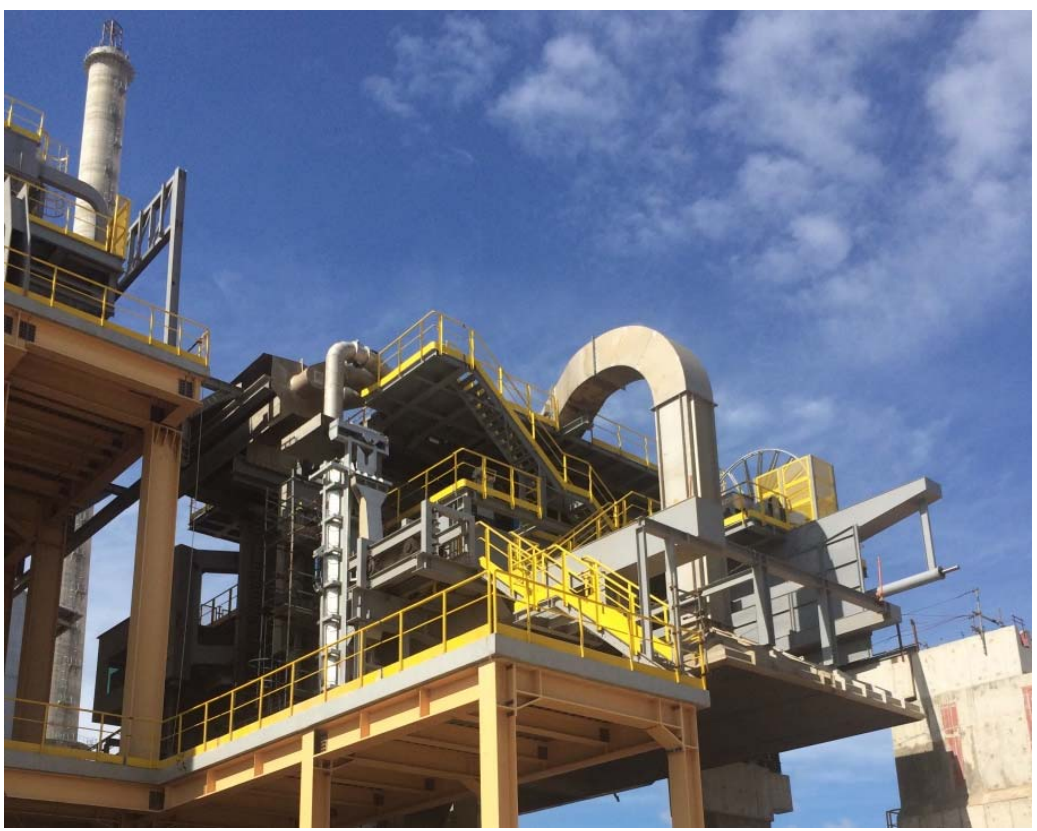

Figure 5. Transfer Car

The main functional units of the machine are listed below:

- Travel drives (boogies)

- Hood system

- Coke guide

- Coke spillages collecting device

- Door extractor (adaptive type)

- Door cleaner

- Frame cleaner

\subsubsection{Pushing emissions control system}

Even if it is installed on the ground, the PECS supplied for CSP has to be considered part of the integrated plant capable to minimize the emissions during pushing.

The design of the bag filter, the collector as well as the belt lifter device has been performed as a unique system with the Coke Transfer Car.

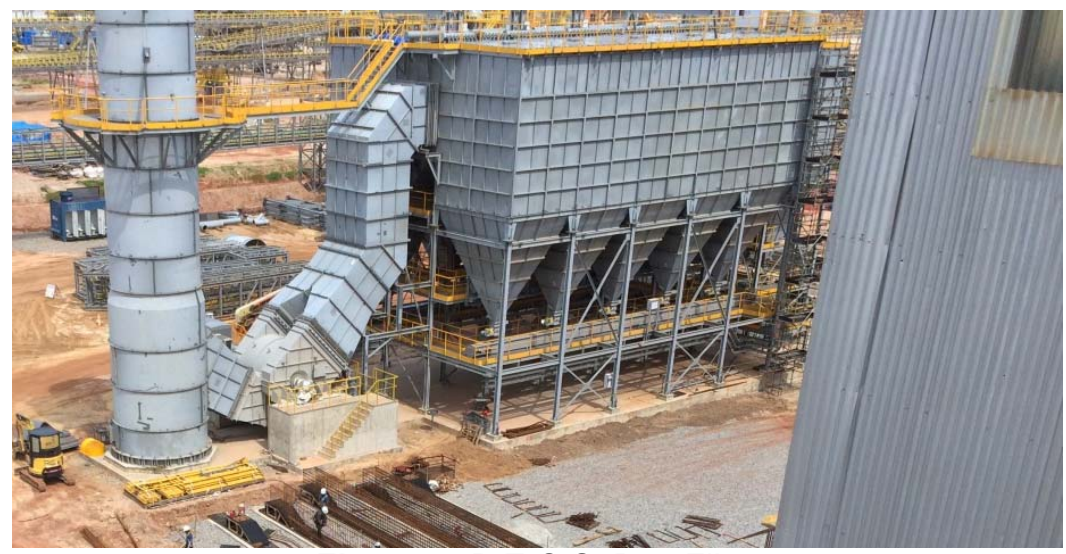

Figure 6. P.E.C.S. Bag Filter 


\subsubsection{Hood system}

- Hood for Door Emission Collection

The coke transfer car is equipped with a door emission collection system. It is the task of the system to collect the emission from the open oven and which are transferred by thermal effect to the top of the machine as well as those emissions which are escaping from the door in cleaning position and to transfer them via the belt lifting car and suction duct to the land based filter plant of the pushing emission control system.

To support the suction special type whirl hoods and booster fans are installed.

- Main Suction Hood above the wet quenching car

The main hood at the transfer car is located above the wet quenching car. The hood is of welded construction and is suspended in the machine supporting structure.

It is the main task of the hood to collect all emissions escaping from the top opening of the coke receiving car, from the breaking coke when it leaves the coke guide and from the coke guide housing and to transfer the dust laden air due to the suction caused by the exhaust fan of the filter plant via the belt lifting car into the collection duct along the battery.

\subsubsection{Coke guide}

The coke guide is arranged on the machine's centre on the track located on the upper machine frame. The inner walls of the coke guide are built up with replaceable $\mathrm{U}$-channels to form a smooth surface. The coke guide trough arranged underneath the sidewalls, which is furnished with replaceable floor and side plates. The coke guide is advanced and returned by means of two hydraulic cylinders. During coke pushing the coke guide is locked via a hydraulically operated device.

The coke guide is housed-in by stainless steel plates to avoid escaping of emissions. On the rear end the housing extends into the main hood. On the front end, on the vertical portion of the coke guide housing spring loaded sealing strips are installed which are pressed against the buck stays during forward movement of the coke guide.

A coke breaker is mounted at the coke guide rear end upper part to transfer the coke cake safely into the coke receiving car.

\subsubsection{Spillage coke collection system}

The machine is equipped with a device, which collects the spillage coke resulting from oven servicing.

The device is located in front of the retracted coke guide and consists out of a movable and tilt able spillage coke collection pan.

At the end of door cycle, the collected residues are dumped directly into the coke guide, ready to be pushed into quenching car at the following pushing cycle.

\subsubsection{Door tools}

Regarding Door Extractor as well as Door and Frame Cleaners, the same technology applied on Pusher Machine is foreseen on Coke Transfer Cars. In order to minimize spare parts, most of the components are common. 


\subsubsection{Coke quenching cars \& locos}

For CSP plant a conventional wet quenching system is foreseen. The Coke Quenching Cars are driven by dedicated Locomotives which have also the function to supply electrical power and compressed air to the discharging flaps driving system.

The coke box of the quench car consists of the floor irons and covering plates that are laid upon them.

The floor irons are laid on respective supports at the loading and unloading side and are secured with brackets that hold them in their position. Due to this a quick exchange of the floor irons is possible without having to touch the base structure.

In order to avoid the entrance of quenching water and coke through the horizontal joints of the steel plates and onto the bogie dedicated drainage channels are foreseen. With the help of this particular design the complete bogie and its structure are effectively protected from quenching water influence.

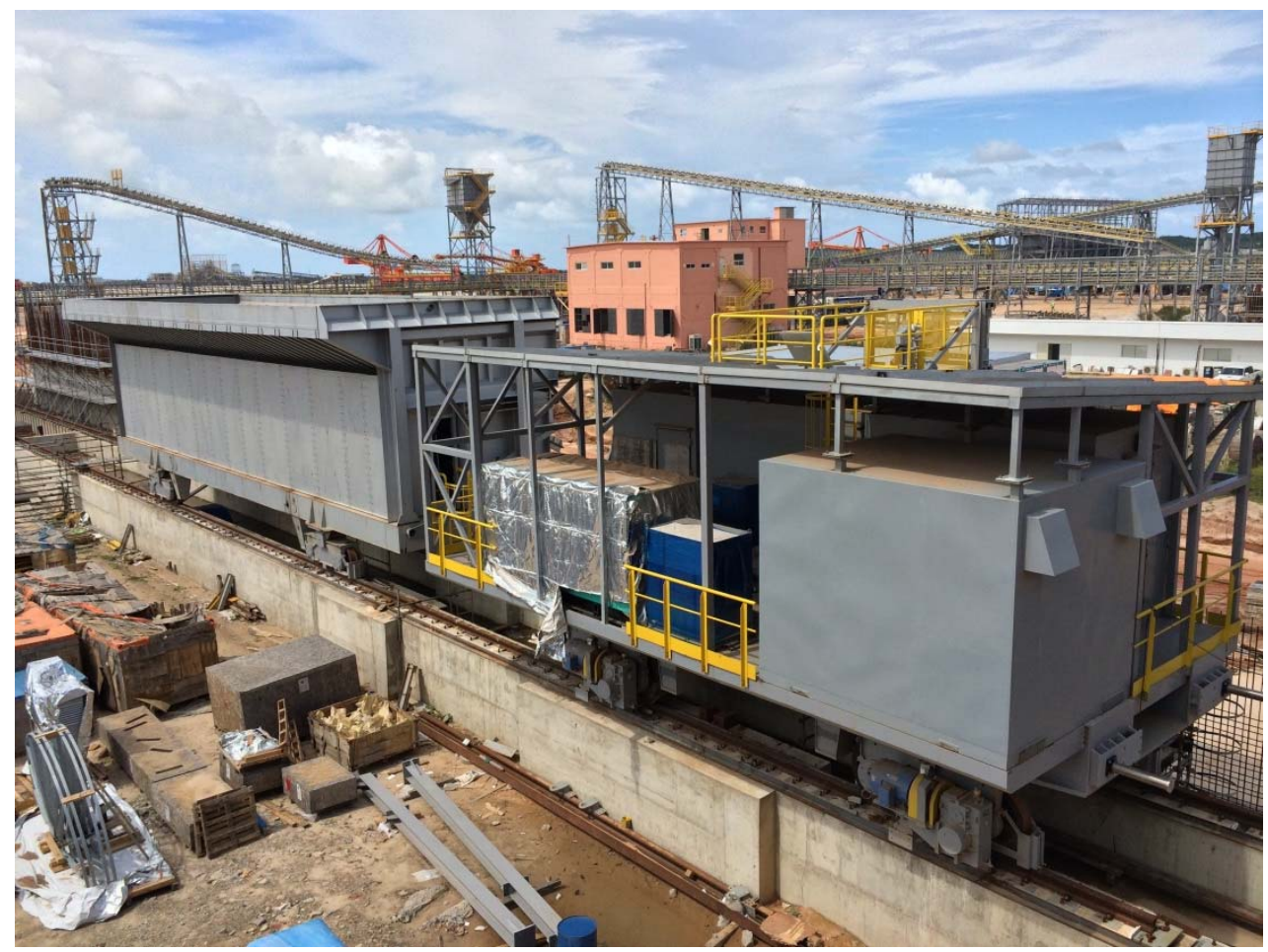

Figure 7. Coke Quenching Car \& Loco

\subsubsection{Door service cars}

In CSP four door service cars (2 for coke side and 2 for pusher side) have been supplied.

With the help of the above devices, all necessary maintenance work can be carried out at the oven doors without utilizing movable platforms, scaffolding or other temporary devices.

The door service cars are hanging from a T-support, which is mounted with cantilever to the battery's buckstays. They are travelled by an electric drive feed by on board batteries.

When not in operation, the whole set of DSCs are parked in coal tower area connected to the power network in order to keep the batteries always charged. 


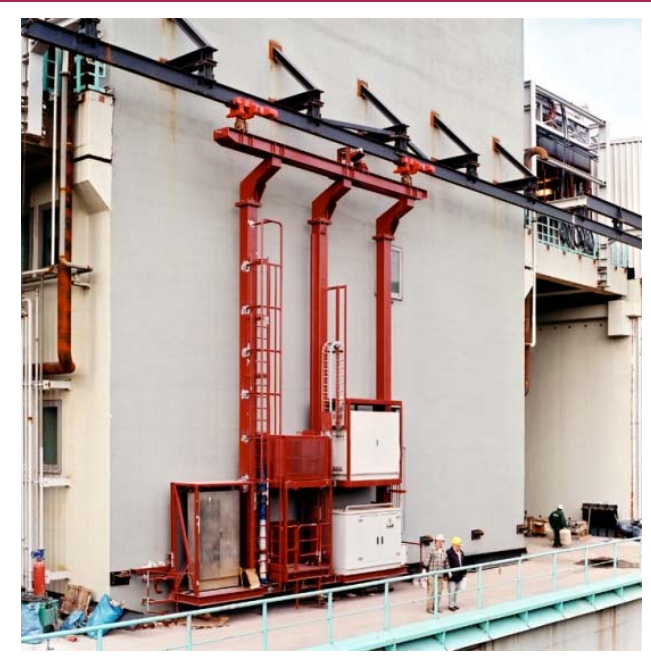

Figure 8. DSC (reference picture)

\section{CONCLUSION}

In CSP, the new Coke Making Plant, which is now under completion, will represent the reference for this technology in Brasil and the whole South America.

In particular for Coke Oven Machines, thanks to the application of modern technologies and to the experience collected by Schalke during more than one hundred years, Paul Wurth has confirmed to be now able to design, supply and hand over to its Customers the most modern machines capable to operate very large coke ovens in a safe, economical and environmentally sustainable way.

The natural consequence has been, for Paul Wurth, the recent acquisition of the order for the new charging car CS11 in CSN (Companhia Siderúrgica Nacional), Volta Redonda.

This important result will allow demonstrating once more the positive environmental impact of updated technologies on existing batteries. 